|| ISSN(online): 2589-8698 || ISSN(print): 2589-868X ||

International Journal of Medical and Biomedical Studies

Available Online at www.ijmbs.info

NLM (National Library of Medicine ID: 101738825)

Index Copernicus Value 2019: 79.34

Original Research Article

Volume 5, Issue 8; August: 2021; Page No. 303-310

\title{
STUDY ON EFFICACY OF PLICATION OF HAEMORRHOIDS
}

\section{Anshul Shah $^{1}$, Sanjeev Singh Choudhary ${ }^{2}$, Lakhmi Chand ${ }^{3}$, K.K. Dhangayach ${ }^{4}$}

${ }^{1}$ Senior Resident, Department of Surgery, SMS Medical College, Jaipur

${ }^{2}$ Senior Resident, Department of Surgery, SMS Medical College, Jaipur

${ }^{3}$ Senior Resident, Department of Surgery, RUHS Medical College, Jaipur

${ }^{4}$ Professor, Department of Surgery, M.G. Medical College, Jaipur

Article Info: Received 06 July 2021; Accepted 17 August 2021

DOI: https://doi.org/10.32553/ijmbs.v5i8.2142

Corresponding author: Anshul Shah

Conflict of interest: No conflict of interest.

\begin{abstract}
Haemorrhoid's and piles are used interchangeably very often but originally the words have entirely different meanings, the term haemorrhoid is derived from Greek word - haemorrhoid which means bleeding which is the prominent symptom in majority of cases. Hippocrates had applied this name to the flow of blood from the venous plexuses of anus. Term piles derived from Latin word pila - a ball, can be optly used for all forms of haemorrhoids because it literally mean every such condition that produce swelling of some kind even if it may not be present externally.
\end{abstract}

Keywords: Haemorrhoid.

\section{Introduction}

Haemorrhoid's is one of the most common conditions seen in surgery clinics. It usually presents as fresh bleeding with or without prolapsing anal tissue per rectum generally associated with constipation.

Haemorrhoid's are cushions of sub mucosal tissue containing venules, arterioles, and smooth muscle fibres present in the anal canal. Three haemorrhoidal cushions are found in the left lateral, right anterior, and right posterior positions. ${ }^{[1]}$

Although haemorrhoidal disease is not fatal, it creates physical and psychological discomfort due to its nagging symptoms and significantly influences the quality of life (QOL) of the diseased person. In addition, frequent recurrence, incomplete elimination of discomfort even after haemorrhoidectomy and postoperative discomfort including pain, made haemorrhoids the biggest problem all over the world that hinders patient's ability to live normally and work efficiently. ${ }^{[2]}$

At least $50 \%$ of the people over the age of fifty have some degree of haemorrhoid formation. ${ }^{[3]}$ According to Ferguson "Hundred percent of the population does suffer from haemorrhoids at least once in their lifetime". ${ }^{[4]}$

Haemorrhoids are thought to function as part of the continence mechanism and aid in complete closure of the anal canal at rest. The prevalence of haemorrhoids when patients are assessed proctoscopically far outweighs the prevalence of symptoms and the term should only be used when patients have symptoms referable to them. ${ }^{[5]}$

Because haemorrhoids are a normal part of anorectal anatomy, treatment is only indicated if they become symptomatic. ${ }^{[1]}$
Haemorrhoids are one of the common disease that affect mankind. Torell stated that seventy percent of population suffering from haemorrhoids and forty percent needed surgical intervention. Incidence of haemorrhoids increases as age advance. Men seem to be affected two to three times more frequently than women. ${ }^{[6]}$

Numerous factors that contribute to haemorrhoid disease are such as constipation with prolonged straining, pregnancy, aging, hereditary, portal hypertension, abdominal tumor, bad defecation habits. ${ }^{[7,8,9]}$

The erect posture of humans is also a predisposing factor. Despite several studies the pathogenesis of haemorrhoids still remains unclear. ${ }^{[10]}$

Based on its anatomical position, severity of disease and symptoms, various classifications of haemorrhoids have been described. Based on anatomical position, there are three main piles (right anterior, right posterior and left lateral position). Additional piles between these are termed as secondary piles.

Another classification as- Piles above the dentate line called internal piles and below the dentate line called as external piles.

There is four degree of haemorrhoid formation-

1. First degree - only bleed without prolapsed.

2. Second degree - prolapse on straining but reduce spontaneously.

3. Third degree - prolapses on straining but have to be replaced manually.

4. Fourth degree - which do not reduce even on manual reduction. 
Based on grading, severity of symptoms, skill and expertisation of surgeon, instrument availability, affordability of patient, various treatment modalities have been proposed.

First degree piles can be treated by conservative approach (i.e. dietary modifications, sitz bath, medicines), sclerotherapy, photocoagulation.

Second degree may be managed through sclerotherapy, plication, rubber band ligation. ${ }^{[11,12]}$ Surgical treatment of haemorrhoids has been suggested for symptomatic grade 2 , grade $3^{\text {rd }}$ and grade $4^{\text {th }}$ haemorrhoidal disease.

Haemorrhoidectomy is usually associated with significant postoperative complications. Due to excision of anoderm below dentate line and perianal skin, severe pain may occur after surgery. Eminent nursing care is required postoperatively, with recovery in at least 1 month. Other complications include heavy bleeding, infection and anal stenosis.

Plication of piles can be performed in symptomatic $2 \mathrm{nd}, 3^{\text {rd }}$ and 4th degree haemorrhoids, this procedure takes very short time without the need of any costly instruments and can be done on elderly patients, so the expenditure by the patient is very less and is a suitable technique for developing and under developed countries.

\section{Material and Methods}

Patients referred to the department of Surgery MGH (OPD, IPD) between JAN 2018 to JUNE 2019 will be included in the study.

\section{Inclusion Criteria}

Patients with all age groups \& either sex with

- Symptomatic Haemorrhoids (2nd to 4th grade) and

- Any associated anorectal pathology such as fissure

- $\quad$ Prolapsed piles

- $\quad$ Thrombosed piles

\section{Exclusion Criteria:}

Patients with

- Piles secondary to anorectal tumor.

- $\quad$ Grade 1 haemorrhoids

- $\quad$ Asymptomatic haemorrhoids Grade 2

\section{Preoperative Preparation :}

- Laxative (Bisacodyl 2 tablet) at night before operation.

- Sodium picosulphate enema to be given early morning on the day of surgery to ensure a clear visualization of anal canal.

- Tetanus prophylaxis as a routine.

\section{Operative Techniques}

With the patient in lithotomy position after appropriate anaesthesia anal stretching, tissue forceps are applied to the skin tags corresponding to the three major piles and retracted to visualise haemorrhoids. A long artery forceps is then applied to the pile mass above the level of pectinate line.

Then the held pile mass is transfixed and ligated with Catgut No.1 Round Body Needle suture at the proximal end of the internal haemorrhoids in order to occlude the superior haemorrhoidal vessel as they enter the internal haemorrhoids. Similar procedure is done to other two pile masses.

If there is any small secondary pile then the same procedure will be done. A small piece of gauge soaked with $2 \%$ Lignocaine jelly and Betadine will be left in anus as dressing. All the patients will be followed up for six months after the procedure.

\section{Results}

\section{Age Incidence}

Most of the patients were between 41 - 60 years of age $(46 \%)$. Youngest age in the series was 20 years old and the oldest was 90 years.

TABLE 1:

\begin{tabular}{|l|c|c|}
\hline AGE & No. & Percentage (\%) \\
\hline $0-20$ & 4 & 3.4 \\
\hline $21-40$ & 44 & 36.7 \\
\hline $41-60$ & 55 & 45.8 \\
\hline $61-80$ & 16 & 13.3 \\
\hline $81-100$ & 1 & 0.8 \\
\hline Total & 120 & 100 \\
\hline
\end{tabular}

Sex Incidence

Males were predominantly affected as compared to females.

TABLE 2:

\begin{tabular}{|l|c|c|}
\hline Gender & No. & Percentage (\%) \\
\hline Male & 90 & 75 \\
\hline Female & 30 & 25 \\
\hline Total & 120 & 100 \\
\hline
\end{tabular}




\section{Presenting Symptoms}

All the patients in this study had bleeding per rectum that was mild to moderate in severity, bright red in colour and appeared in drops or as stream after the act of defecation or during defecation. Mass coming per rectum was the second most common symptom followed by constipation.

\begin{tabular}{|l|c|c|}
\hline \multicolumn{1}{l}{ TABLE 3 } \\
\hline Symptoms & No. & Percentage \\
\hline Bleeding P/R & 120 & 100 \\
\hline Mass Coming P/R & 112 & 93.3 \\
\hline Constipation & 95 & 79.2 \\
\hline Painful Defecation & 12 & 10 \\
\hline Discharge & 6 & 5 \\
\hline Cough & 10 & 8.3 \\
\hline
\end{tabular}

\section{Duration of Symptoms}

$54 \%$ of the patient had symptoms of duration of 6 months to 3 years. Longest duration of symptoms in this series was 7 years while shortest duration was 15 days.

TABLE 4

\begin{tabular}{|l|c|c|}
\hline $\begin{array}{l}\text { Duration of } \\
\text { symptoms }\end{array}$ & No. of patients & Percentage \\
\hline$<1$ Month & 8 & 6.7 \\
\hline $1-6$ months & 20 & 16.7 \\
\hline 6 months -1 year & 29 & 24.2 \\
\hline $1-3$ years & 36 & 30 \\
\hline 3-6 years & 22 & 18.3 \\
\hline$>6$ years & 5 & 4.2 \\
\hline
\end{tabular}

\section{Previous Treatments Taken}

91.8\% patients received some form of conservative treatment in the form of ointments and laxatives and felt partially relieved. These were the patients having symptoms of longer duration due to intermittent relief they got from conservative treatment.

TABLE 5

\begin{tabular}{|l|c|c|}
\hline Previous treatment & No. of patients & Percentage \\
\hline Ointments & 50 & 41.7 \\
\hline Ointment + Laxative & 34 & 28.3 \\
\hline Laxative & 25 & 20.8 \\
\hline None & 11 & 9.2 \\
\hline Total & 120 & 100 \\
\hline
\end{tabular}

\section{Family History}

In 20 patients, one or more relatives in their family had suffered from haemorrhoids.

TABLE 6

\begin{tabular}{|l|c|c|}
\hline Family History & No. of patients & Percentage \\
\hline Positive & 20 & 16.7 \\
\hline Negative & 100 & 83.3 \\
\hline Total & 120 & 100 \\
\hline
\end{tabular}

Number Of Primary Haemorrhoids

Out of 120 patients, about $80 \%$ had all the three primary piles while in $14.2 \%$ patients two piles were present.

TABLE 7

\begin{tabular}{|l|c|c|}
\hline Number of primary haemorrhoids & No. of patients & Percentage \\
\hline Three & 96 & 80 \\
\hline Two & 17 & 14.2 \\
\hline One & 7 & 5.8 \\
\hline Total & 120 & 100 \\
\hline
\end{tabular}

\section{Position Of Haemorrhoids}

Most common position of pile is 11 o'clock followed by 3 o'clock. 
TABLE 8

\begin{tabular}{|l|c|c|}
\hline Position of haemorrhoids & No. of patients & Percentage \\
\hline 3'O Clock & 112 & 93.3 \\
\hline 7'O Clock & 101 & 84.2 \\
\hline 11'O Clock & 116 & 96.7 \\
\hline Secondary & 14 & 11.7 \\
\hline
\end{tabular}

\section{Degree of Haemorrhoids}

Out of 120 patients, $80 \%$ had 3 rd degree piles, $13.4 \%$ had $2^{\text {nd }}$ degree piles and rest had $4^{\text {th }}$ degree piles.

TABLE 9

\begin{tabular}{|l|c|c|}
\hline Degree of Haemorrhoids & No. of patients & Percentage \\
\hline IIb Degree & 16 & 13.4 \\
\hline III Degree & 97 & 80.8 \\
\hline IV Degree & 7 & 5.8 \\
\hline Total & 120 & 100 \\
\hline
\end{tabular}

\section{Additional Findings}

$10 \%$ patients had fissure and $5.8 \%$ patients had fistula as an additional findings at anorectal junction.

TABLE 10

\begin{tabular}{|l|c|c|}
\hline Additional Findings & No. of patients & Percentage \\
\hline Fistula & 7 & 5.8 \\
\hline Fissure & 12 & 10 \\
\hline None & 101 & 84.2 \\
\hline
\end{tabular}

\section{Procedure Done}

In this study, $90.8 \%$ patients underwent plication and $9.2 \%$ pateints underwent an additional procedure along with plication.

TABLE 11

\begin{tabular}{|l|c|c|}
\hline Name Of Procedure & No. & Percentage \\
\hline Plicaton & 109 & 90.8 \\
\hline Plication With Lscis & 6 & 5 \\
\hline Plication With Fistulectomy & 5 & 4.2 \\
\hline Total & 120 & 100 \\
\hline
\end{tabular}

\section{Post-Operative Complications}

In this study of plication of piles $86.7 \%$ of cases had no pain. $3.3 \%$ of cases who had pain were also suffering from fissure and fistula. These patients had pain during defecation which also continued afterwards requiring analgesics. The pain resolved in $10 \%$ of patients with analgesic after a week.

TABLE 12

\begin{tabular}{|l|c|c|}
\hline Postoperative Complications & No. of patients & Percentage \\
\hline Slight discomfort & 13 & 10.8 \\
\hline Pain & 16 & 13.3 \\
\hline Insignificant bleeding PR & 5 & 4.2 \\
\hline Discharge & 3 & 2.5 \\
\hline Retention of urine & 1 & 0.8 \\
\hline Prolapse & 0 & 0 \\
\hline Constipation & 0 & 0 \\
\hline None & 81 & 67.5 \\
\hline
\end{tabular}

\section{Long Term Results}

The results of plication of piles are satisfactory. $1.7 \%$ of the patients had pain for which 1 patient had to be operated for fissure and in other one analgesics had to be continued for long term. $2.5 \%$ of the patients developed bleeding and prolapse again in which $1.7 \%$ patients underwent the procedure again and rest managed conservatively. $1.6 \%$ of patients developed constipation and re bleeding and were managed conservatively.

TABLE 13

\begin{tabular}{|l|c|c|}
\hline Long term follow up complicatons & No. of patients & Percentage \\
\hline Constipation & 1 & 0.8 \\
\hline Haemorrhoids & 3 & 2.5 \\
\hline Pain & 2 & 1.7 \\
\hline Rebleeding & 1 & 0.8 \\
\hline None & 113 & 94.2 \\
\hline
\end{tabular}


Regular proctoscopy revealed that immediately after plication, the piles masses became bigger and deeper in colour and look congested upto the 7th day after which there was shrinkage. At about the end of 8th week, when all the sutures were absorbed the plicated piles masses look segmented and shrinked. At 12th to 15th week we found that the shrinked piles masses were gradually replaced by fibrous bands.

\section{Discussion}

During our study on plication of hemorrohoids , consisting of 120 patients who were being treated during January 2018 to June 2019, have been evaluated on personal examination and questionnaire.

In the present series more than $80 \%$ of the patients were between 20-60 years of age and none below 20 years.

Patients above 80 years of age were only $0.8 \%$. Similar age incidence had been observed by Awojobi et al, Dowidar et al, Ezzeldeen et al. ${ }^{[12,13,14]}$

Haemorrhoids are more common in males in our study which was similar to the results obtained by Vyas et al, Dowidar et al, Ezzeldeen et al. ${ }^{[15,13,14]}$

All the patients who were included in the present study complained mainly of bleeding per rectum. Similar high incidence of complaint of bleeding had also been observed by other workers Awojobi et al $(100 \%)$, Patnaik et al $(80 \%)$, Dowidar et al (78\%) and Ezzeldeen et al (50\%). $[12,16,13,14]$

In our study $50 \%$ of the patient had symptoms of duration of 6 months to 2 years, however Agrawal S. et al reported the 54\% patients with symptoms presenting less than 6 months.

Agrawal S. et al reported $60 \%$ patients received some form of conservative treatment. ${ }^{[17]}$ However, in our study $91.8 \%$ patients received some form of conservative treatment in the form of ointments and laxatives and felt partially relieved leading to longer duration of symptoms due to intermittent relief.

Most common position of haemorrhoids is11 o'clock followed by 3 o'clock in our study, however, Agrawal S. et al reported most common position of hemorrohoids is 3 o'clock followed by 7 o'clock. ${ }^{[17]}$

\section{Operative Procedures}

Plication of hemorrohoids is a simple and effective procedure for the treatment of haemorrhoids.

The advantages are that it's simple and easy to learn, can be done as a day care surgery, no postoperative pain, no postoperative retention of urine, no significant bleeding during and after operation, early recovery, immediate control of symptoms, no anal stenosis and ideal for patients having portal hypertension and bleeding disorders.

\section{Simple and Easy Procedure}

Plication of hemorrohoids can be performed in $2^{\text {nd }}, 3^{\text {rd }}$ and $4^{\text {th }}$ degree haemorrhoids. A short period of about 5-7 minutes is required to plicate haemorrhoids once anaesthesia is given. It does not require costly equipment's. Expenditure for the operation is almost negligible.

\section{Postoperative Pain}

In $86.7 \%$ of patients in the present study there was no postoperative pain and $3.3 \%$ had pain but these patients had been treated simultaneously for fissure-in-ano and fistula. Dowidar et al, observed that $8.7 \%$ of patients had pain in placation of piles whereas, $54.55 \%$ had pain in excision and ligation of piles. ${ }^{[13]}$ Agrawal S. et al, observed that $94 \%$ of cases had no pain, $6 \%$ of cases who had pain and were also suffering from fissure. ${ }^{[17]}$ Pattanayak S. et al observed in his study 484 patients $(95.47 \%)$ got relieved from postoperative pain by 72 hours, whereas in conventional method only 178 patients $(35.10 \%)$ got relief from postoperative pain by 72 hours. ${ }^{[18]}$

\section{Intra-Operative and Postoperative Bleeding}

The amount of blood loss during the procedure was almost nil.

There was insignificant postoperative bleeding per rectum in $4.2 \%$ of the patients which resolved by conservative treatment.

$\mathrm{Nag} \mathrm{KH}$ et al, observed postoperative bleeding in $4.3 \%$ cases. ${ }^{[19]}$

Similar finding as that of present study was observed by

Awojobi et al, Patnaik et al and Ezzeldeen et al, in the study of plication. ${ }^{[12,16,14]}$

Pattanayak $\mathrm{S}$ et al observed intra and postoperative bleeding occurred in $(1.37 \%)$ in contrast to conventional method in which $(13.4 \%)$ cases were having bleeding. ${ }^{[18]}$

Agrawal S. et al, observed no postoperative bleeding. ${ }^{[17]}$

\section{Postoperative Retention of Urine}

Single case of postoperative retention of urine was noted in our series $80 \mathrm{y} / \mathrm{m}$ who was also suffering from fistula in ano and $\mathrm{bph}$. Since in this procedure there is no incision or excision of piles so there is no disturbance of nerve supply to perineal area.

Dowidar et al, reported $4 \%$ postoperative urinary retention in plication of piles and $23 \%$ in excision and ligation of piles. $^{[13]}$

After plication of piles Ezzeldeen et al, reported 9.37\% patients had urinary retention. ${ }^{[14]}$

Agrawal S. et al, observed no case of postoperative retention of urine. ${ }^{[17]}$

\section{Postoperative Management}

In this procedure no postoperative management was required. Once the effect of anaesthesia was over they were allowed to take full diet. All patients were given lactulose 3 teaspoon in the night and first bowel action usually followed on the first postoperative day. There was no need 
of postoperative dressing, enema and digital dilatation. Oral antibiotics (ciprofloxacin) were given prophylactically for 5 days to prevent abscess. Hot sitz bath was advised and laxative was given along with smuth ointment. Routine analgesics were not prescribed.

In Patnaik's, study $88 \%$ patients had painless first bowel action whereas, only $2 \%$ patients who had undertaken classical haemorrhoidectomy had.

Dowidar et al observed first bowel action in plication of piles on first postoperative day whereas on 2nd postoperative day in excision and ligation of piles in most of the patients. ${ }^{[13]}$

Pattanayak S et al observed $82.06 \%$ of patients had painless bowel movements , $13.01 \%$ patients had painful bowel movements with blood in stool, $4.93 \%$ patients had painful bowel movements without blood in stool after plication method whereas only $3.16 \%$ of patients had painless bowel movements, $28.40 \%$ patients had painful bowel movements with blood in stool, $68.44 \%$ patients had painful bowel movements without blood in stool after conventional method. ${ }^{[18]}$

\section{Early Recovery}

The procedure is performed as a day-care procedure. After plication of piles patients can be allowed to go home on the same day and were allowed to join office work from next day. But due to (inconvenience) poor transport system and spinal anaesthesia many patients had gone home the next day.

In Farag's, study on plication of piles, he observed that the mean stay in the hospital was 3.6 days against 7.2 days who had undergone classical haemorrhoidectomy. ${ }^{[20]}$

In Patnaik's, study all patients were allowed to go home on the same day and time off work was 1 day. ${ }^{[16]}$

Pattanayak $\mathrm{S}$ et al observed reported all the patients who underwent plication stayed in the hospital for 1-2 days, and were able to carry out their daily work after 5-7 days but in conventional method in his study the patient had to stay in the hospital for 5-9 days, and were able to carry out their daily work after 14-26 days. ${ }^{[18]}$

\section{Follow up}

Our cases have been followed up for 6 months in the present study. The results were satisfactory. $1.7 \%$ of the patients i.e 2 patients had pain for which 1 had to be operated for fissure and in other one analgesics had to be continued for long term. $2.5 \%$ of the patients developed bleeding and prolapse again in which $1.7 \%$ patients underwent the procedure again and rest managed conservatively. $1.6 \%$ of patients developed constipation and re bleeding and were managed conservatively.

No long term complication/ recurrence were noted. Incontinence to flatus, faeces, and stenosis and recurrence of other symptoms were not seen.

In Farag's, study and Dowidar et al, study on plication of piles no long term complication was observed for a year. [20,13]
Patnaik, in his study on plicaton of piles had bleeding in $0.5 \%$ patient on long-term follow-up for a year whereas in haemorhoidectomy it was in $33 \%$ of patients. ${ }^{[16]}$

Pattanayak S et al observed $97.8 \%$ patients had no longterm complications, only $2.16 \%$ patients had long-term recurrent bleeding, no patients had incontinence to faeces/flatus, anal continence, recurrence after plication whereas after conventional method $75.8 \%$ patients had no long-term complications, $7.69 \%$ patients had recurrent bleeding, $6.90 \%$ had incontinence to faeces/flatus, $2.36 \%$ had anal stenosis, $7.29 \%$ had recurrence as long-term complications. ${ }^{[18]}$

\section{Conclusion}

The treatment of haemorrhoids has been widely discussed in the various literatures. The various methods are being employed by majority of surgeons throughout the world.

However, optimal choice of surgical method for treating such a wide disease require that the approach should be so simple so as to suit calibre of all surgeons with varying experience and be so convenient so as to be readily acceptable to all patients and yet be effective in a large number of patients and should be cost effective also.

From the above discussion it is quite clear that plication is a relatively painless procedure in comparison to the conventional methods as nor the skin, or the sphincter is dealt with. Post-operative problems such as bleeding, incontinence, anal stenosis or recurrence of symptoms were not found in the plication method. This technique requires a very short hospital stay and very short length of time off work. Because of these executions, and safety in the hands of relatively inexperienced, this can strongly be recommended for rural India where sophisticated facilities are usually not adequate. Plication of piles can be performed in symptomatic 2nd, $3^{\text {rd }}$ and 4 th degree haemorrhoids, this procedure takes very short time without the need of any costly instruments and can be done on elderly patients, so the expenditure by the patient is very less and is a suitable technique for developing and under developed countries.

Plication of piles aims at answering a simple, safe but an effective method of surgical treatment of haemorrhoidal disease that suits second, third and fourth degree of symptomatic haemorrhoids; in addition to establish a nonexpensive method.

\section{References}

1. Schwartz - Colon, Rectum, and Anus Kelli M. Bullard Dunn and David A. Rothenberger

2. Lee JH, Kim HE, Shin JY, Song YM. Factors Associated with Haemorrhoids in Korean Adults: Korean National Health and Nutrition Examination Survey.

3. Goligher JC. Surgery of anus, rectum, colon. $5^{\text {th }}$ edition. Bailliare Tindall, London; 1984: 98-149.

4. Ferguson JA, Heaton JR.Closed haemorrhoidectomy. Dis Colon Rectum; 1959; 2: 176. 
5. Lunniss PJ. The anus and anal canal. In: Williams NS, Bulstrode CJK, O'Connell PR. Bailey and Love's Short practice of Surgery. 25th ed. London, UK: Edward Arnold (Publishers) Ltd; 2008:12401272.

6. Parks, AG. Pathogenesis and treatment of fistula in ano. Br Med J. ;1961;1:463-467.

7. Jacobs DM, Bubrick MP, Onstad GR, et al. The relationship of haemorrhoids to portal hypertension. Dis Colon Rectum; 1980 Nov 1; 23(8): 567-9.

8. Acheson RM. Haemorrhoids in the adult male: a small epidemiological study. Guys Hosp Rep;1960; 109: 184-195.

9. Johanson JF, Sonnenberg A. The prevalence of haemorrhoids and chronic constipation: an epidemiologic study. Gastroenterology;1990 Feb 28; 98(2): 380-386.

10. Brisinda G.how to treat haemorrhoids BMJ. 2000:321:582-3pmc free article (pubmed)

11. Barron J.Office ligation treatment of haemorrhoids. Diseases of the colon and rectum; $1963 ; 96: 109-113$

12. Awojobi, Omyomba A. Modified pile suture in the outpatient treatment of haemorrhoids. Am Societ Colon Rectal Surgeon. 1983; 26:957.
13. Dowidar N, Ebada A, Rayah AF, Soud AM. Pile suture technique for treatment of haemorrhoids verses ligation excision haemorrhoidectomy; a randomized trial evaluating clinical effects and anal sphincter manometry. Egyptian J Surg. 2004;23(2):159-66.

14. Ezzeldeen MM. Plication of haemorrhoids. Egyptian J Surg. 2005; 24(1).

15. Vyas KC. Sclerotherapy and banding for the treatment of haemorrhoids. Indian J Coloproctology. 1997; 11:2.

16. Patnaik SP, Mangual R. Plication as a procedure for treatment of piles. Indian J Coloproctol. 1997; 11:236.

17. Agarwal S, Mehta R, Joshi CP. A study on plication of piles. Int Surg J 2016; 3:786-91.

18. Pattanayak S, Kumar M, Patro SK, Behera MK. Plication: an innovative method of treating piles. Int Surg J 2019;6:4056-61.

19. $\mathrm{Ng} \mathrm{KH}$, Ho KS, Ooi BS, Tang CL, Eu KW. Experience of 3711 stapled haemorrhoidectomy operation. Br J Surg. 2006; 93(2):226-30.

20. Farag AE: Pile suture: a new technique for the treatment of haemorrhoids. Brit J Surg. 1978; 65: 293-5. 